\title{
Source mechanism of a VLP event immediately before the 2014 eruption of Mt. Ontake, Japan
}

\author{
Yuta Maeda ${ }^{1 *}$, Aitaro Kato ${ }^{1,2}$, Toshiko Terakawa ${ }^{1}$, Yoshiko Yamanaka ${ }^{1}$, Shinichiro Horikawa ${ }^{1}$, Kenjiro Matsuhiro ${ }^{1}$ \\ and Takashi Okuda ${ }^{1}$
}

\begin{abstract}
The phreatic eruption of Mt. Ontake in 2014 was preceded for $25 \mathrm{~s}$ by a very long period (VLP) seismic event recorded at one broadband and three short-period seismic stations located within $5000 \mathrm{~m}$ of the summit. We performed waveform inversion of the event within a frequency band of $0.1-0.5 \mathrm{~Hz}$ that pointed to an ENE-WSW opening (NNW-SSE striking) subvertical tensile crack at a depth of 300-1000 m beneath the region of the eruptive vents. This crack orientation is consistent with alignments of volcano-tectonic (VT) earthquake hypocenters and eruptive vents as well as normal faulting (E-W tension) focal mechanisms of the VT earthquakes. We interpreted these results as follows: the VLP source crack was one of a group of preexisting faults that was opened immediately before the eruption because of the passage of ascending gas from depth to the surface.
\end{abstract}

Keywords: Phreatic eruption, Mt. Ontake, VLP event, Waveform inversion

\section{Background}

Very long period (VLP) seismic events are volcanoseismic events with dominant periods of 2-100 s that typically occur at shallow $(\sim 1000 \mathrm{~m})$ depths. Examinations over the last two decades of the source processes of VLP events indicate that the events are generated by volume changes and movements of magmatic-hydrothermal fluids (e.g., Chouet and Matoza 2013). Therefore, analyses of VLP events at a volcano are crucial for understanding fluid states and behaviors beneath the volcano. Some VLP events are associated with phreatic eruptions (e.g., Legrand et al. 2000; Jolly et al. 2010; Maeda et al. 2015) as well as various types of magmatic eruptions (e.g., Chouet et al. 2003, 2005, 2010).

Mt. Ontake (Fig. 1) is the second highest $(3067 \mathrm{~m}$ above sea level) active volcano in Japan. Recent activity at Mt. Ontake is characterized by phreatic eruptions in 1979, 1991, and 2007. The 2007 eruption was preceded by a VLP event 2 months earlier (Nakamichi et al. 2009).

\footnotetext{
* Correspondence: maeda@seis.nagoya-u.ac.jp

'Earthquake and Volcano Research Center, Graduate School of Environmental Studies, Nagoya University, D2-2 (510) Furo-cho, Chikusa-ku, Nagoya 464-8601, Japan

Full list of author information is available at the end of the article
}

After a dormant period of 7 years, a phreatic eruption started at around 11:52:30 Japan Standard Time (JST) on 27 September 2014 (Additional file 1). Although a swarm of volcano-tectonic (VT) earthquakes had been observed starting 1 month before the eruption, the number of long-period seismic events had been small and no detectable VLP event had been recorded until 11:45 on the day of the eruption, when an intense volcanic tremor and earthquake swarm as well as summituplift tilt started (Kato et al. 2015).

In the present study, we identified a clear VLP event immediately before the onset of the eruption. We performed waveform inversion of the VLP event assuming several candidate source mechanisms. The inversion solution was then compared with several other studies of the Mt. Ontake 2014 eruption to examine the source process of the VLP event.

\section{Data and methods}

At the time of the eruption in 2014, four seismic stations were operating within $5000 \mathrm{~m}$ of the summit (Fig. 1). Station ROPW was equipped with a Guralp CMG-3T broadband seismometer (natural period $30 \mathrm{~s}$ ), and the other three stations were equipped with short-period

\section{实 Springer}




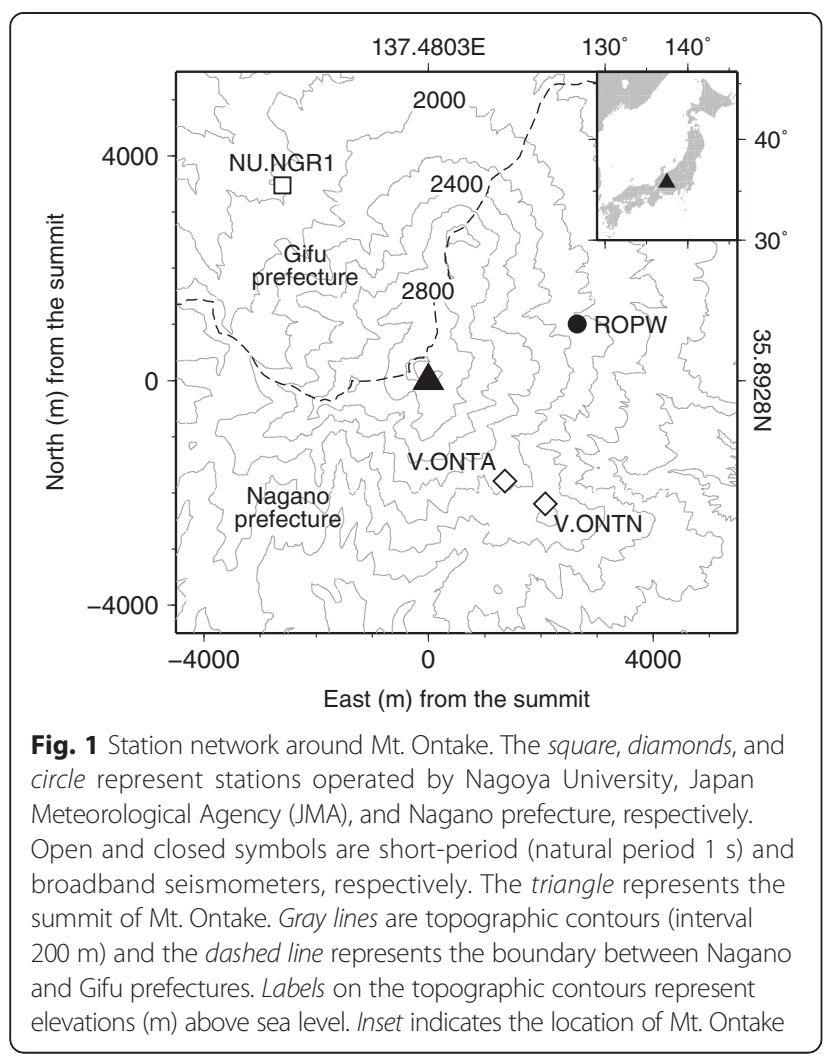

sensors (natural period $1 \mathrm{~s}$ ) with damping constants of 0.5 (V.ONTA, V.ONTN) and 0.7 (NU.NGR1). The data were sampled at $100 \mathrm{~Hz}$ and telemetered to Nagoya University. The seismometer at ROPW is estimated to be misoriented by $8^{\circ}$ counterclockwise (Additional file 2), which we corrected for prior to the following analyses.

In Fig. 2, we plot band-passed $(0.1-0.5 \mathrm{~Hz})$ vertical seismograms for the four stations from around the time of the eruption onset. A VLP event was recorded during 11:52:05-11:52:11, approximately 25-19 s before the eruption onset. The waveforms of this event are consistent from station to station and exhibit a simple Ricker-like shape, suggesting that a waveform inversion of this event would yield relatively stable results. Another VLP event was recorded during 11:52:32-11:53:02, but the waveforms of this event were long-lasting and complicated compared with those of the first VLP event (Fig. 2). Since the second event took place after the eruption onset, various surface phenomena may have contaminated the waveforms. We therefore analyzed only the first VLP event (11:52:05-11:52:11) that took place immediately before the eruption. The VLP event was most clearly visible in the $0.1-0.5 \mathrm{~Hz}$ frequency band (Fig. 3).

We undertook a waveform inversion of the first VLP event using three component seismograms from the four stations. From individual raw seismic records covering the time period 11:00-12:00, we corrected for instrumental responses, applied a high-pass filter of $0.05 \mathrm{~Hz}$,

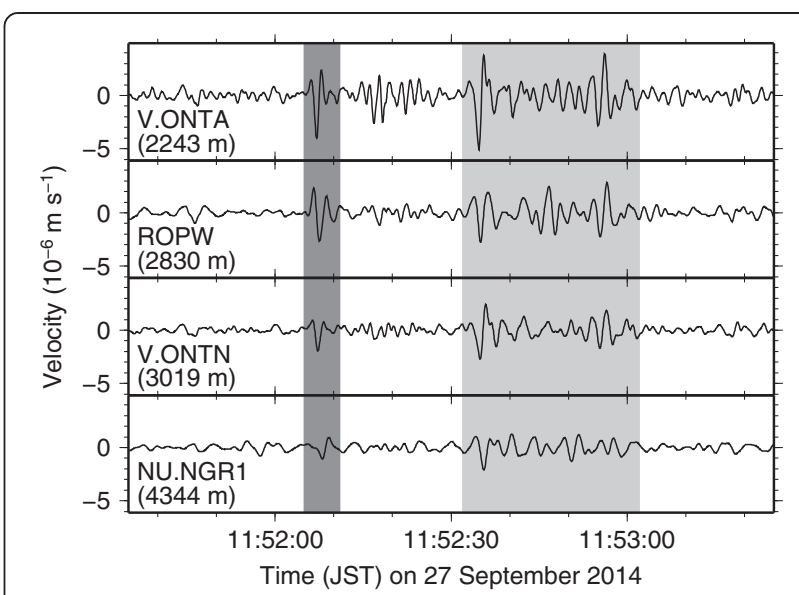

Fig. 2 Vertical velocity waveforms around the eruption onset time in a $0.1-0.5-\mathrm{Hz}$ band. The instrumental responses were corrected. Distances from the summit to individual stations are shown with the station codes. Dark and light shaded areas represent the VLP event analyzed in the present study (11:52:05-11:52:11) and another VLP event not analyzed in this study (11:52:32-11:53:02), respectively

integrated to displacement, and applied a band-pass filter of $0.1-0.5 \mathrm{~Hz}$. The high-pass filter was used to avoid amplifications of long-period noise by the integration. Both filters (the high-pass and band-pass) were Butterworth type with two poles and zero phase shift. After the band-pass filtering, we resampled the data at $10 \mathrm{~Hz}$, selected a time window of 11:52:03-11:52:13, and applied a cosine taper to the last $1 \mathrm{~s}$ of the window.

We calculated the Green functions using a finite difference code of Maeda and Kumagai (2013). A grid spacing of $40 \mathrm{~m}$ and a time step of $0.004 \mathrm{~s}$ were used. We assumed a homogeneous structure with a $P$-wave velocity $V_{\mathrm{p}}=3000 \mathrm{~m} \mathrm{~s}^{-1}$, an $S$-wave velocity $V_{\mathrm{s}}=V_{\mathrm{p}} / \sqrt{3}=1732 \mathrm{~m} \mathrm{~s}^{-1}$, and a rock density $\rho_{\mathrm{s}}=2300 \mathrm{~kg} \mathrm{~m}^{-3}$ (Gardner et al. 1974). The 3D topography used in the computation was based on a 0.04 " ' grid digital elevation model (DEM) produced by the Geospatial Information Authority of Japan (GSI). We used a coordinate conversion tool available from the GSI website to calculate the DEM grid nodes and station locations in a Cartesian coordinate system. We used a conversion for Nagano prefecture (zone 8 in the tool) because the majority of the stations were on the side of Nagano prefecture (Fig. 1).

Since the number of stations is limited, we assumed several candidate source mechanisms (Nakano and Kumagai 2005) instead of independently solving for all six moment tensor components. The mechanisms considered were an isotropic source, a tensile crack, a volume change of a pipe, and a single force. The normal vector of the crack, the symmetry axis of the pipe, and the direction of the single force were consistently represented by two angles, $\theta$ and $\phi$, which are measured from the vertical and counterclockwise from the east, 


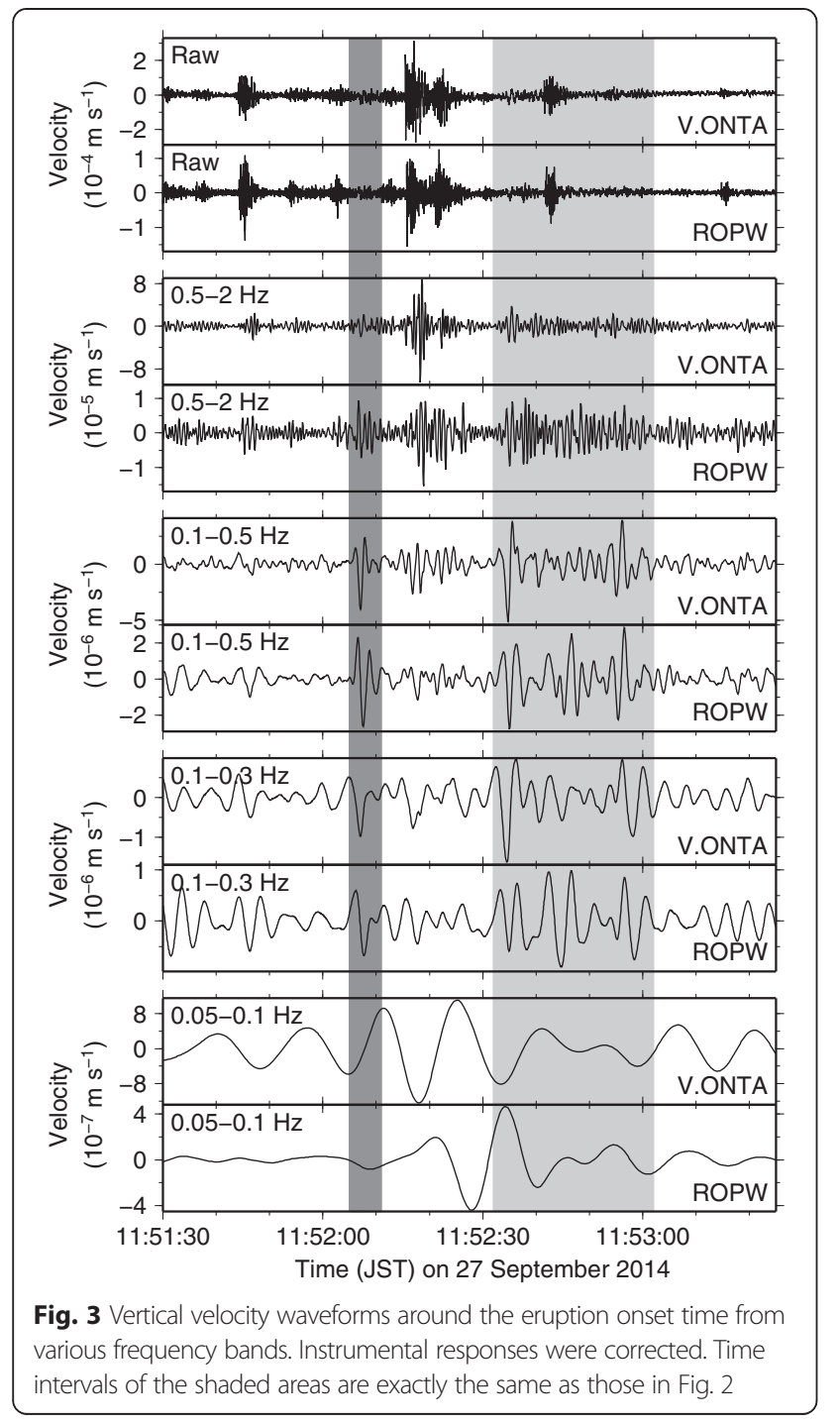

respectively. The unknowns to be solved for each source mechanism are the centroid source location, $\theta, \phi$, and the source time function. We have two classes of source time functions. One is a filtered source time function (FSTF) that is band-limited $(0.1-0.5 \mathrm{~Hz})$ because of the band-pass filter applied to the data before the waveform inversion. The other is a deconvolved form of the source time function (DSTF) (Nakano et al. 2008; Maeda et al. 2015) in which the effects of the band-pass filter are removed. The DSTF better describes the source process, whereas the direct solution of the waveform inversion is the FSTF.

We solved for these unknowns using the following procedure. For each source mechanism, we conducted grid searches for the centroid source location and $(\theta, \phi)$. We applied three levels of grid searches, from rough to fine grid intervals (Table 1). For each grid node, we performed a linear least-squares inversion in the frequency
Table 1 List of the grid searches. East and north are measured from the summit. Elevation is above sea level. The residual $E$ is based on Eq. (2) for the best-fit solution of each search. The first search was conducted for all four source mechanisms, and the best-fit tensile crack solution is shown. The second and third searches were conducted only for a tensile crack

\begin{tabular}{lllll}
\hline Parameter & Minimum & Maximum & Interval & Best-fit solution \\
\hline First search & & & & \\
East & $-3200 \mathrm{~m}$ & $3200 \mathrm{~m}$ & $200 \mathrm{~m}$ & $-400 \mathrm{~m}$ \\
North & $-3200 \mathrm{~m}$ & $3200 \mathrm{~m}$ & $200 \mathrm{~m}$ & $-400 \mathrm{~m}$ \\
Elevation & $-3200 \mathrm{~m}$ & $2800 \mathrm{~m}$ & $200 \mathrm{~m}$ & $2000 \mathrm{~m}$ \\
$\theta$ & $0^{\circ}$ & $90^{\circ}$ & $15^{\circ}$ & $75^{\circ}$ \\
$\varphi$ & $0^{\circ}$ & $345^{\circ}$ & $15^{\circ}$ & $0^{\circ}$ \\
$E$ & & & & $56.1 \%$ \\
Second search & & & & \\
East & $-1400 \mathrm{~m}$ & $600 \mathrm{~m}$ & $40 \mathrm{~m}$ & $-320 \mathrm{~m}$ \\
North & $-1400 \mathrm{~m}$ & $600 \mathrm{~m}$ & $40 \mathrm{~m}$ & $-440 \mathrm{~m}$ \\
Elevation & $1000 \mathrm{~m}$ & $2800 \mathrm{~m}$ & $40 \mathrm{~m}$ & $2040 \mathrm{~m}$ \\
$\theta$ & $30^{\circ}$ & $120^{\circ}$ & $5^{\circ}$ & $80^{\circ}$ \\
$\varphi$ & $-45^{\circ}$ & $45^{\circ}$ & $5^{\circ}$ & $5^{\circ}$ \\
$E$ & & & & $55.2 \%$ \\
Third (final) search & & & \\
East & $-720 \mathrm{~m}$ & $80 \mathrm{~m}$ & $40 \mathrm{~m}$ & $-360 \mathrm{~m}$ \\
North & $-840 \mathrm{~m}$ & $-40 \mathrm{~m}$ & $40 \mathrm{~m}$ & $-480 \mathrm{~m}$ \\
Elevation & $1640 \mathrm{~m}$ & $2440 \mathrm{~m}$ & $40 \mathrm{~m}$ & $2040 \mathrm{~m}$ \\
$\theta$ & $65^{\circ}$ & $95^{\circ}$ & $1^{\circ}$ & $79^{\circ}$ \\
$\varphi$ & $-10^{\circ}$ & $20^{\circ}$ & $1^{\circ}$ & $6^{\circ}$ \\
$E$ & & & & $55.1 \%$ \\
\hline
\end{tabular}

domain (Auger et al. 2006) to compute the FSTF and synthetic waveforms. We evaluated the goodness of the waveform fits with the Akaike Information Criterion (AIC) (Akaike 1974) calculated as

$$
\begin{aligned}
& \mathrm{AIC}=2 N K \ln E+2(K+M), \\
& E=\left[\sum_{n=1}^{N} \sum_{k=1}^{K}\left(u_{\mathrm{nk}}^{\mathrm{obs}}-u_{\mathrm{nk}}^{\mathrm{syn}}\right)^{2} / \sum_{n=1}^{N} \sum_{k=1}^{K}\left(u_{\mathrm{nk}}^{\mathrm{obs}}\right)^{2}\right]^{1 / 2},
\end{aligned}
$$

where $N$ is the number of waveform traces, $M$ is the number of free parameters to define the orientation of the source, $K$ is the number of data samples, and $u_{\mathrm{nk}}$ obs and $u_{\mathrm{nk}}{ }^{\text {syn }}$ are the $k$ th data samples of the observed and synthetic band-passed waveforms of the $n$th data trace, respectively. In our case, $N=12$ (three components at the four stations), $K=101$ (11:52:03-11:52:13 with a 0.1-s sampling), and $M=0$ for the isotropic source and $M=2(\theta$ and $\phi)$ for the other three source mechanisms. The grid search gives the best source mechanism, centroid source location, and $(\theta, \phi)$ corresponding to the 
minimum AIC value. For this best model, the FSTF was already obtained by the procedure above, and the final step is to determine the DSTF. To stabilize our estimate of the DSTF, we imposed a constraint that the DSTF is expressed by a ramp, triangular, or Gaussian function. We applied a band-pass filter of $0.1-0.5 \mathrm{~Hz}$ to these trial functions and compared the resultant band-passed waveforms with the FSTF to determine the best trial function. The best duration and timing of the function were estimated by grid searches. More details of our procedure to estimate the DSTF are described in Maeda et al. (2015).

\section{Results and discussion}

First, we show the results of our first rough grid search (Table 1). Among the four candidate source mechanisms, a tensile crack yielded the minimum AIC value (Table 2). For the tensile crack, the spatial distribution and crack orientation dependence of the residual showed only a single global minimum and no local minima (Fig. 4). These results suggest that the tensile crack is the most plausible source mechanism of the four candidates, and finer searches for the best location and orientation of the crack are needed only around the global minimum of the first search.

Based on this evaluation, we used only the tensile crack around the global minimum of the first search for our finer grid searches (Table 1) to save computational costs. In Fig. 4, the residuals obtained by the three grid searches are overlain. The best solution of the final search was $360 \mathrm{~m}$ west and $480 \mathrm{~m}$ south of the summit $(137.4763 \mathrm{E}, 35.8884 \mathrm{~N})$ and $2040 \mathrm{~m}$ above sea level with $\theta=79^{\circ}$ and $\phi=6^{\circ}$. The surface elevation at the grid node of the DEM data nearest to the estimated source location was $2641 \mathrm{~m}$ above sea level, suggesting that the source depth was approximately $600 \mathrm{~m}$ beneath the surface. The residual $E$ (Eq. (2)) of the best-fit solution was $55.1 \%$, and most of the solutions with $E \leqq 58 \%$ were around $\pm 500 \mathrm{~m}$ and $\pm 20^{\circ}$ (Fig. 4). The small residual region was extended to the west because of the station distribution. Within this uncertainty, the source parameters were consistent with an ENE-WSW opening (NNW-SSE striking) subvertical tensile crack beneath the southwest flank at an elevation of around $2000 \mathrm{~m}$ above sea level (300-1000 $\mathrm{m}$ below the surface). The

Table 2 Comparison of Akaike Information Criterion (AIC) values among the four assumed source mechanisms. The residuals $E$ are based on Eq. (2). Results of the first search (Table 1) are shown

\begin{tabular}{lll}
\hline Mechanism & $E(\%)$ & AIC value \\
\hline An isotropic source & 70.5 & -585 \\
A tensile crack & 56.1 & -1024 \\
A volume change of a pipe & 61.3 & -765 \\
A single force & 60.7 & -945 \\
\hline
\end{tabular}

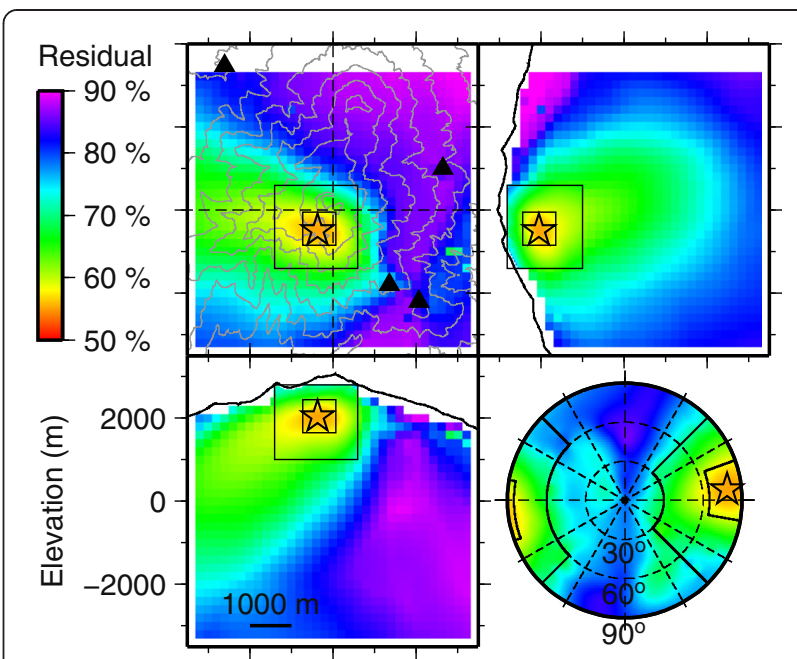

Fig. 4 Spatial distribution and crack orientation dependence of the residuals between observed and synthetic waveforms. The residuals $E$ are calculated by Eq. (2). Results of the three grid searches are overlain. The second and third search domains are represented by the solid outlines. The crack orientation dependence is plotted against the crack normal direction projected onto the upper hemisphere. Triangles and stars are the station locations and the best-fit solution of the final search, respectively. Gray lines are the topographic contours (interval $200 \mathrm{~m}$ )

observed waveforms were well-fitted by the synthetic waveforms computed from the best-fit solution except that it underestimates the high-frequency oscillation amplitudes (Fig. 5).

In Fig. 6a, we show the source time functions (both the FSTF and DSTF) of the best-fit solution. Fourier spectra of the source time functions show that low frequency amplitudes are suppressed in the FSTF because of the band-pass filter (Fig. 6b), resulting in a DC offset between the FSTF and DSTF (Fig. 6a). Since the DSTF is band-unlimited and better describes the source process

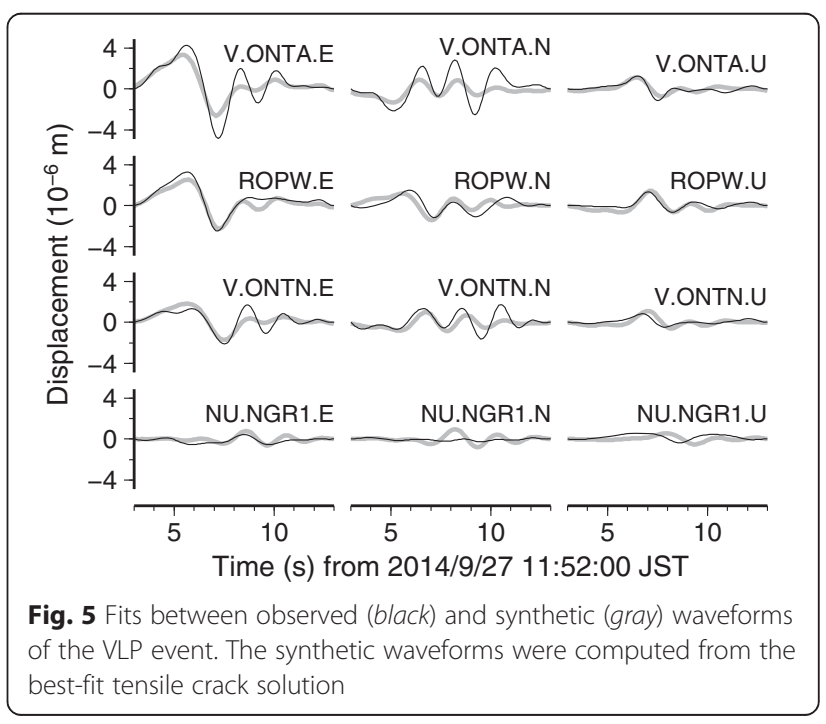




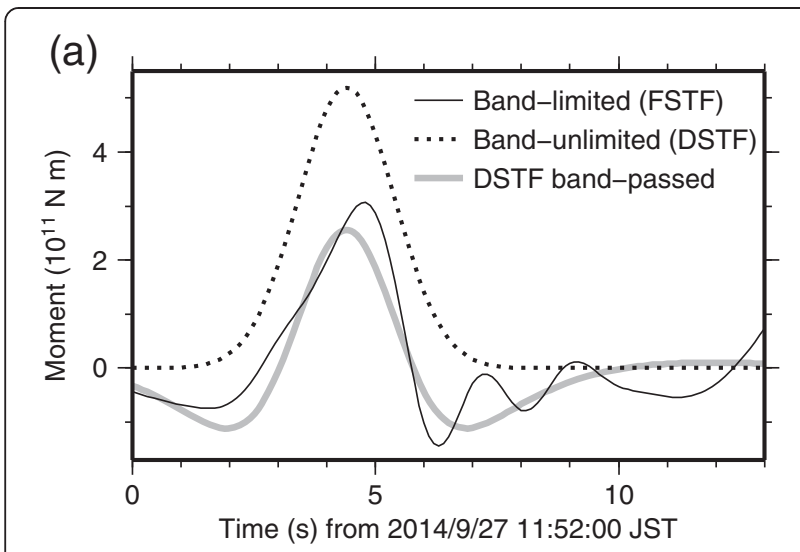

(b)

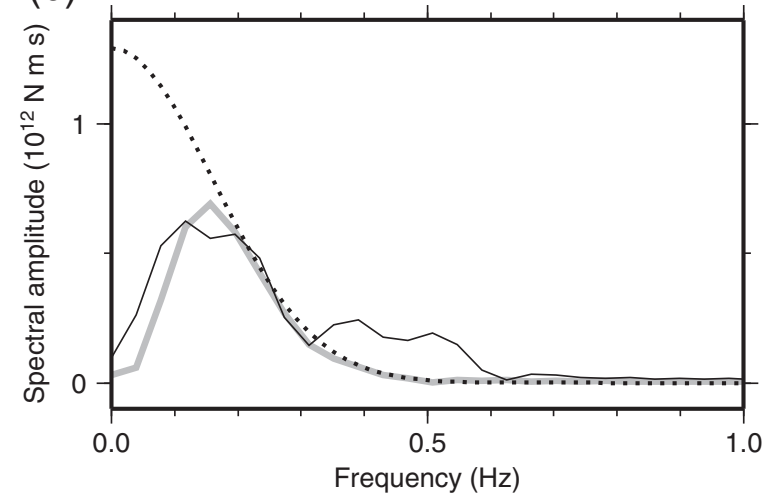

Fig. 6 Source time functions of the VLP event. a The black line is a band-limited source time function directly obtained by the waveform inversion (FSTF), and the dotted line is the deconvolved form of the source time function (DSTF), which is band-unlimited and represents the source process. Gray line is the DSTF, band-pass filtered at $0.1-0.5 \mathrm{~Hz}$, which gives a measure of the goodness of the DSTF such that a better DSTF yields a better fit between the black and gray lines. b Fourier amplitude spectra for the three curves of Fig. $6 \mathrm{a}$

(Nakano et al. 2008; Maeda et al. 2015), we use the DSTF for our interpretation. The estimated DSTF is a Gaussian function of 7.0-s duration with a maximum amplitude of $5.2 \times 10^{11} \mathrm{~N} \mathrm{~m}$ (Fig. 6a). A tensile crack is expressed by a moment tensor with three eigenvalues, $(\lambda+2 \mu) \Delta V(t), \lambda \Delta V(t)$, and $\lambda \Delta V(t)$, where $\lambda$ and $\mu$ are the Lame constants and $\Delta V(t)$ is a time history of the volume change of the crack (e.g., Aki and Richards 2002). Our definition of the source time functions of the tensile crack is $\mu \Delta V(t)$. Therefore, dividing the maximum amplitude of the DSTF $\left(5.2 \times 10^{11} \mathrm{~N} \mathrm{~m}\right)$ by $\mu=\rho_{\mathrm{s}} V_{\mathrm{s}}^{2}=6.9 \mathrm{GPa}$ yields a volume change of $75 \mathrm{~m}^{3}$. This volume change is explained by a $0.01-\mathrm{m}$ opening of a $100-\mathrm{m}$-long and 75 $\mathrm{m}$-wide crack, although the decomposition of the volume change into the crack opening and size is not unique.

In Fig. 7, we compare the estimated VLP source with other observations. The hypocenters of VT earthquakes relocated by Kato et al. (2015) are aligned in an NNW-SSE direction, subparallel to the strike direction of the VLP

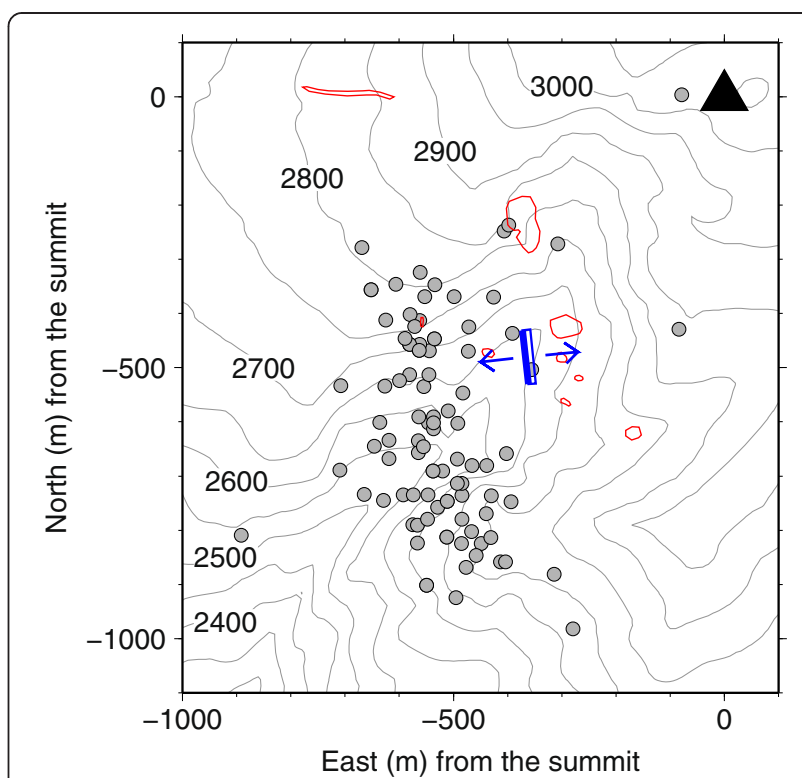

Fig. 7 Comparison of our waveform inversion solution with other observations. Blue color represents the estimated VLP source crack; the upper edge and opening direction of the crack are plotted by the tick line and the arrows, respectively. Gray circles are hypocenters of VT earthquakes in August and September 2014 relocated by Kato et al. (2015). We did not use any magnitude threshold, and the magnitude ranged from -0.5 to +1.5 . The triangle represents the summit of Mt. Ontake. Red and gray lines are the outlines of eruptive vents estimated by GSI (2014) and topographic contours (interval $50 \mathrm{~m}$ ), respectively. Labels on the topographic contours represent elevations (m) above sea level

source crack. The absolute location difference between the VLP source and the densely populated region of the VT hypocenters may be explained by location errors of both events. The location and orientation of the VLP source crack coincide with the eruptive vent distribution estimated by GSI (2014) (Fig. 7). In summary, the VLP source, VT hypocenters, and eruptive vents all show an NNW-SSE trend. This direction is subparallel to one of the maximum shear directions in the regional stress field estimated by Terakawa et al. (2015). The crack orientation of the 2014 VLP source is also consistent with the waveform inversion solution of the VLP event of 2007 (Nakamichi et al. 2009), although the 2007 VLP event had a larger seismic moment $(1.5 \times$ $10^{14} \mathrm{~N} \mathrm{~m}$ ) and a lower source elevation $(600 \mathrm{~m}$ above sea level). Terakawa et al. (2015) showed that over the month prior to the eruption, normal faulting focal mechanisms with E-W to ENE-WSW tension directions were dominant among the VT earthquakes, suggesting a local stress field consistent with the ENE-WSW opening of the VLP source crack.

Based on these comparisons, we can explain the VLP event as follows. Because of the regional stress field, preexisting seismic (shear) faults may have aligned along the NNW-SSE direction. These faults could have acted as 
pathways for ascending gas from depth to the surface immediately before the 2014 eruption because migration through the preexisting faults is easier than creating a new pathway by rupturing an intact rock. A permeability difference between the fault zone and the surrounding rock could have resulted in gas accumulations and resultant tensile openings of the originally shear faults, and one of these events could have been detected as the VLP event. The local stress field beneath Mt. Ontake prior to the eruption suggested by the focal mechanisms of the VT earthquakes (E-W to ENE-SWS tension; Terakawa et al. 2015) may have been conducive to crack opening. The DSTF showed inflation followed by deflation of the crack (Fig. 6a). The inflation may have been attributed to the accumulation of the gas, whereas the deflation may have been due to the gradual escape of the gas from the crack toward the surface.

We identified similar VLP events in the seismic record from ROPW between 11:50 and the onset of the eruption, although these events had amplitudes that were too small to analyze by waveform inversion. This suggests that the gas may have sequentially passed through several preexisting seismic faults, leading to the generation of the VLP events. More details will be discussed after we complete our ongoing analyses of the summit-uplift tilt that started at 11:45 (Kato et al. 2015).

\section{Conclusions}

We undertook waveform inversion of the VLP event of 11:52:05-11:52:11 JST, spanning the 25-19-s time interval prior to the onset of the phreatic eruption of 27 September 2014. We used seismograms containing the $0.1-0.5-\mathrm{Hz}$ frequency band from the nearest four stations located within $5000 \mathrm{~m}$ of the summit. We assumed four candidate source mechanisms (an isotropic source, a tensile crack, a volume change of a pipe, and a single force) and conducted grid searches for the source location and orientation. The inversion solution was consistent with an ENE-WSW opening (NNW-SSE striking) subvertical tensile crack at a depth of 300-1000 m beneath the eruptive vent region. The estimated strike of the crack is subparallel to the alignments of VT earthquake hypocenters and eruptive vents as well as one of the maximum shear directions in the regional stress field. The crack opening orientation is consistent with the normal faulting (E-W to ENE-WSW tension) focal mechanisms of the VT earthquakes that occurred beneath Mt. Ontake over the month before the eruption. Based on these observations, we suggest that the VLP source crack was one of a set of preexisting faults formed along the maximum shear direction of the regional stress field (NNW-SSE). Before the eruption, the faults may have been more readily opened because of a local stress consistent with ENE-WSW tension. Under this set of conditions, the crack may have opened because of the inflow of ascending gas from depth and then closed when the gas escaped from the crack toward the surface immediately before the eruption.

\section{Additional files}

Additional file 1: Estimating the eruption onset time. This file describes our estimate of the eruption onset time.

Additional file 2: Horizontal misorientations of seismometers. This file describes our estimates of the horizontal misorientations of seismometers.

\section{Competing interests}

The authors declare that they have no competing interests.

\section{Authors' contributions}

YM conducted the data analyses and drafted the manuscript. AK provided the numerical data for the VT earthquake hypocenters (Fig. 7) and helped to interpret the results of analyses through discussions and comparisons with his own analyses of the seismicity. TT helped to interpret the analyses through discussions and comparisons with her own analyses of the regional stress field. YY helped to improve the manuscript through discussion. SH worked to maintain the station network and helped to estimate the reliable sensor parameters. KM and TO worked to maintain the station network. All the authors read and approved the final manuscript.

\section{Acknowledgements}

We used seismic and infrasonic records obtained by the Japan Meteorological Agency, Nagano prefecture, and the National Research Institute for Earth Science and Disaster Prevention. We used numerical data of the topography, eruptive vent locations, and Nagano-Gifu prefecture boundary from GSI. We used a coordinate conversion tool available from the GSI website. This study was supported by the Earthquake Research Institute cooperative research program. Comments by Robin Matoza and an anonymous reviewer helped to improve the manuscript.

\section{Author details}

${ }^{1}$ Earthquake and Volcano Research Center, Graduate School of Environmental Studies, Nagoya University, D2-2 (510) Furo-cho, Chikusa-ku, Nagoya 464-8601, Japan. 'Earthquake Research Institute, The University of Tokyo, 1-1-1 Yayoi, Bunkyo-ku, Tokyo 113-0032, Japan.

Received: 16 September 2015 Accepted: 12 November 2015 Published online: 24 November 2015

\section{References}

Akaike H. A new look at the statistical model identification. IEEE Trans Autom Control. 1974;19(6):716-23. doi:10.1109/TAC.1974.1100705.

Aki K, Richards P. Quantitative seismology. 2nd ed. Sausalito: University Science; 2002. Auger E, D'Auria L, Martini M, Chouet B, Dawson P. Real-time monitoring and massive inversion of source parameters of very long period seismic signals: an application to Stromboli Volcano, Italy. Geophys Res Lett. 2006;33, L04301. doi:10.1029/2005GL024703.

Chouet BA, Matoza RS. A multi-decadal view of seismic methods for detecting precursors of magma movement and eruption. J Volcanol Geotherm Res. 2013;252:108-75. doi:10.1016/j.jvolgeores.2012.11.013.

Chouet B, Dawson P, Ohminato T, Martini M, Saccorotti G, Giudicepietro F, et al. Source mechanisms of explosions at Stromboli Volcano, Italy, determined from moment-tensor inversions of very-long-period data. J Geophys Res. 2003;108(B1):2019. doi:10.1029/2002JB001919.

Chouet B, Dawson P, Arciniega-Ceballos A. Source mechanism of Vulcanian degassing at Popocatepetl Volcano, Mexico, determined from waveform inversions of very long period signals. J Geophys Res. 2005;110(B7), B07301. doi:10.1029/2004JB003524.

Chouet BA, Dawson PB, James MR, Lane SJ. Seismic source mechanism of degassing bursts at Kilauea Volcano, Hawaii: results from waveform inversion in the 10-50 s band. J Geophys Res. 2010;115(B9), B09311. doi:10.1029/2009JB006661 
Gardner GHF, Gardner LW, Gregory AR. Formation velocity and density-the diagnostic basics for stratigraphic traps. Geophysics. 1974;39(6):770-80. doi:10.1190/1.1440465

Geospatial Information Authority of Japan (2014) Correspondence on the volcanic activity of Mt. Ontake (in Japanese). http://www.gsi.go.jp/BOUSAI/ h26-ontake-index.html. Accessed 9 June 2015

Jolly AD, Sherburn S, Jousset P, Kilgour G. Eruption source processes derived from seismic and acoustic observations of the 25 September 2007 Ruapehu eruption - North Island, New Zealand. J Volcanol Geotherm Res. 2010;191 (1-2):33-45. doi:10.1016/j.jvolgeores.2010.01.009.

Kato A, Terakawa T, Yamanaka Y, Maeda Y, Horikawa S, Matsuhiro K, Okuda T (2015) Preparatory and precursory processes leading up to the 2014 phreatic eruption of Mount Ontake, Japan. Earth Planets Space (in press)

Legrand D, Kaneshima S, Kawakatsu H. Moment tensor analysis of near-field broadband waveforms observed at Aso Volcano, Japan. J Volcanol Geotherm Res. 2000;101(1-2):155-69. doi:10.1016/S0377-0273(00)00167-0.

Maeda Y, Kumagai $\mathrm{H}$. Effects of water domains on seismic wavefields: a simulation case study at Taal volcano, Philippines. Earth Planets Space. 2013;65(2):85-96. doi:10.5047/eps.2012.07.004.

Maeda Y, Kumagai H, Lacson R, Figueroa MS, Yamashina T, Ohkura T, et al. A phreatic explosion model inferred from a very long period seismic event at Mayon Volcano, Philippines. J Geophys Res Solid Earth. 2015;120(1):226-42. doi:10.1002/2014JB011440

Nakamichi H, Kumagai H, Nakano M, Okubo M, Kimata F, Ito Y, et al. Source mechanism of a very-long-period event at Mt Ontake, central Japan: response of a hydrothermal system to magma intrusion beneath the summit. J Volcanol Geotherm Res. 2009;187(3-4):167-77. doi:10.1016/j. jvolgeores.2009.09.006.

Nakano M, Kumagai H. Waveform inversion of volcano-seismic signals assuming possible source geometries. Geophys Res Lett. 2005;32, L12302. doi:10.1016/ S0377-0273(02)00499.

Nakano $M$, Kumagai $H$, Inoue $H$. Waveform inversion in the frequency domain for the simultaneous determination of earthquake source mechanism and moment function. Geophys J Int. 2008;173(3):1000-11. doi:10.1111/j.1365-246X.2008. 03783.x.

Terakawa T, Kato A, Yamanaka Y, Maeda Y, Horikawa S, Matsuhiro K, Okuda T (2015) Temporal changes in earthquake focal mechanism solutions following the 2014 eruption of the Mt. Ontake volcano. In: Proceedings of the Japan Geoscience Union Meeting, Makuhari, 24-28 May 2015

\section{Submit your manuscript to a SpringerOpen ${ }^{\circ}$ journal and benefit from:}

- Convenient online submission

- Rigorous peer review

- Immediate publication on acceptance

- Open access: articles freely available online

- High visibility within the field

- Retaining the copyright to your article

Submit your next manuscript at $>$ springeropen.com 